DEMOCRACIA BURGUESA E POLÍTICA ECONÔMICA: o trágico caso grego1

\title{
Salvatore D'Acunto
}

Seconda Università degli Studi di Nápoles (SUN)

Francesco Schettino

Seconda Università degli Studi di Nápoles (SUN)

\section{DEMOCRACIA BURGUESA E POLÍTICA ECONÔMICA: o trágico caso grego}

Resumo: O artigo aborda dimensões da relação democracia burguesa e politica econômica, tendo como referência privilegiada da análise a questão da dívida grega explicitada no ano de 2015. Enfatiza que o problema da dívida não se limita à experiência da Grécia ou aos outros países do sul da Europa, ao contrário, é muito mais abrangente e é da própria natureza da produção capitalista, ainda mais em fase de crise. Conclui que o caso grego evidencia que a democracia burguesa, cada vez mais, é reduzida a um ritual substancial sem sentido. Frente à população da Grécia, esmagada entre a adesão às demandas das instituições representativas do bloco de capitais do continente e o respeito à "delegação" atribuída pelo eleitorado, o governo grego vem resolvendo o conflito curvando-se a chantagens e endossando, neste momento, o regime de "suspensão" à soberania democrática.

Palavras-chave: Crise capitalista, referendo grego, democracia burguesa.

\section{BOURGEOIS DEMOCRACY AND POLITICAL ECONOMY: the tragic greek case}

Abstract: The article discusses dimensiones of the relation of bourgeois democracy and political aconomy, having as prime reference of teh analysis the question of greek debt explained in the year 2015. Emphasizes that the problem of the debt is not limited to the experience of Greece and of other Southern Europeam Countries, by contrast, is much more comprehensive ando fother Southern European countries, by contrast, is much more comprehensive and is in the nature of capitalist production, especially in crisis phase. Concludes that the Greek case shows that bourgeois democracy, increasingly, it is reduced to a ritual substantially pointless. Front of the population of Greece, crushed between adherence to the demands of representative institutions of the continent's capital block and respect for "delegation" given by the electorate, the Greek government is solving the conflitc bowing to blackmail and endorsing at this time, the regime of "suspension" democratic sovereignty.

Key words: Capitalist crisis, Greek referendum, bourgeois democracy. 


\section{INTRODUÇÃO}

O verão de 2015 foi objeto de eventos entre os mais dramáticos e interessantes dos últimos anos, pelo menos no que concerne à imprevisibilidade com a qual estes se sucederam. A explosão de uma das bolhas especulativas que começaram sua formação na China nas últimas décadas, juntamente as progressivas desvalorizações atuadas pelo Banco Central local, estimulou uma série de quedas na cadeia das economias mundiais que, rapidamente, quebraram as poucas expectativas de melhora que, no início do ano, tinham sido apresentadas como válidas pelos ilusionistas da comunicação capitalista. O ocorrido está longe de se considerar esgotado e, sem dúvida alguma, ao longo dos próximos anos e meses, as dificuldades já apontadas - mesmo que só uma fração destas tenho sido aprofundada dentro do gigante asiático, terão efeitos relevantes na estrutura do modo de produção do capital.

Ao mesmo tempo em que estes eventos de peso histórico se verificavam, na Europa estava acontecendo à chamada tragédia grega. Esta, no início, se apresentou como contraposição frontal do bloco mais conservador do capital ligado ao euro, aparentemente irresolúvel, mas depois estabilizada, de forma aparentemente solucionada, mediante dramáticos acontecimentos políticos. Através de evidente reviravolta de grande fração da proposta eleitoral com a qual a própria Syriza tinha sido eleita e, sobretudo, desconsiderando publicamente o êxito do referendum do dia 5 de julho, que tinha sancionado a hostilidade dos gregos em relação às propostas da troika, Tsipras - também ficando de mãos atadas ao atuar de forma diferente - aceitou, de fato, o memorando proposto pelas instituições.

Esta série de eventos mostra claramente como as instituições burguesas - entre elas a assim chamada democracia - são, por definição, gerenciadas pela classe dominante e de como suas evoluções em termos de política econômica sejam, por consequência, o resultado das relações de classe, portanto, reflexo, também, da fase de acumulação do capital e da conflitualidade interimperialista.

Assim, é a análise de determinações, relações e expressões dessa série de eventos que se dedica o presente artigo.

\section{DESDE A CRISE DA DÍVIDA PÚBLICA ATÉ A VITÓRIA DA SYRIZA}

Conforme apontado em outro artigo publicado na Revista de Políticas Públicas, certamente, a questão grega não teve origem em 2015, mas sua situação profundamente crítica afunda suas raízes em um passado nem tão remoto (SCHETTINO, 2014). Em particular, se considerarmos a chamada crise da dívida, precisamos retroceder até 2010, ano em que a economia grega e, de modo mais geral, o capital ligado ao euro tinham sido abalados pela concorrência do outro lado do oceano. Assim, como apontava o próprio Wall Street Journal no fevereiro daquele ano, importantes representantes do capital ligado ao dólar, durante jantar acontecido em Manhattan, entenderam que as condições gerais da economia mundial apresentavam ocasião, talvez única, para se programar um ataque especulativo em grande estilo, até mais relevante do que já tinha acontecido em detrimento dos tigres asiáticos, Rússia e Brasil, na metade da década de 1990 (PULLIAN; KELLY; MOLLE, 2010).

Apesar disso, com significativa descontinuidade em relação ao passado, precisa salientar-se que, dessa vez, o objetivo não estava representado pelas economias dos países terceiros, mas pelos apêndices mais fracos da área do euro. Explicitava-se, assim, o já exacerbado e evidente conflito existente, há mais de uma década, entre capitais das áreas cambiais contrapostas (euro e dólar) e que caracteriza o imperialismo na fase atual.

Através da ferramenta do credit default swap (um dos produtos financeiros de derivativos mais em uso), esses sicários do capital decidiram golpear as economias dos países do sul da Europa, sobretudo a Grécia. A assim chamada ideia do jantar (lit. The idea dinner) baseia-se em investir maciçamente na desvalorização do euro que, do máximo atingido em 2009 de 1,50 dólares, nas previsões dos especuladores, poderia ter chegado perto de 1 dólar depois de ação arquitetada que revelou a contradição mais aguda da área meridional da Europa, isto é, a dívida dos países que fazem parte da moeda única. Pelo analisado, foi o chefe do fundo especulativo da Brigade Capital, Donald Morgan quem inseriu no endividamento grego o gap que mostrava o efeito dominó que enfraqueceu a moeda e levou a desestabilização mais geral, coisa que aconteceu depois.

Precisa-se refletir agora sobre as questões que induziram as pessoas a agir dessa forma ambiciosa e direta ao coração de uma das fileiras dominantes do modo de produção capitalista, ou seja, as da área do euro. Muito já se disse sobre os truques contáveis do governo grego conservador de Costas Karamanlis (politicamente muito próximo de Ângela Merkel), que tinha declarado um déficit público muito inferior a $12,7 \%$ (valor quatro vezes mais alto em relação aos níveis máximos estipulados na área do euro através do pacto de estabilidade), situação descoberta e declarada em seguida institucionalmente pelo governo social-democrático do Pasok de Papandreou. Isto representava uma situação generalizada de crise de toda a economia grega - sobre a qual pesa um nível de ilegalidade quase próxima de $50 \%$ do total (a assim chamada economia submersa), considerado o espantoso colapso geral da produção.

O potencial evidente calote do estado grego, então, foi o pretexto que incentivou a inevitável depreciação dos títulos do governo (junk bonds), que 
logo determinou uma diminuição do valor, isto é, uma drástica redução da riqueza fictícia dos donos desse tipo de investimento - naquela época, sobretudo os bancos europeus - situação que desencadeou o pânico em todos os mercados da bolsa. Em especial, precisa-se frisar como grande parte dos empréstimos, que nos últimos anos enfraqueceu e aumentou a dívida do Estado grego, chegou de bancos alemães ligados ao governo alemão e garantida pelo eixo político Merkel-Karamanlis. Esta é uma das razões pelas quais as instituições europeias violaram desde o início os regulamentos estipulados por elas próprias, concedendo empréstimos para permitir aos credores amigos à restituição de pelo menos parte do crédito já oferecido. Conforme veremos mais adiante, de toda forma, o problema, do ponto de vista do capital ligado ao euro, foi quase definitivamente resolvido com o mecanismo do Esfs, que em três anos conseguiu migrar os títulos lixo do governo grego dos bancos privados em direção às contas públicas, criando uma ulterior vulnerabilidade para aqueles estados já com problemas próprios ${ }^{2}$.

Todavia, é importante relembrar que, o problema da dívida não se limita à experiência da Grécia ou aos outros países do sul da Europa, ao contrário, é muito mais abrangente e é da própria natureza da produção capitalista de per si, ainda mais em fase de crise: devemos reconsiderar a dívida que caracteriza a maioria dos Estados do mundo. Segundo estudos diversos, juntando as dívidas, privadas e públicas, dos EUA, Inglaterra, Japão e Canadá estas alcançam a 130 mil bi \$ que, para esclarecer mais, é o dobro do valar total de produção das mercadorias do mundo. Desse valor, cerca da metade é norte-americana, enquanto o total das dívidas dos Estados europeus chega a $40 \mathrm{mil}$ bi \$ aproximadamente: em relação a esses valores, evidentemente, os quase 400 bi $\$$ da dívida grega são uma quantia sem expressão e isto mostra, mais uma vez, como a situação grega não representava de per si um problema irresolúvel, apesar das dificuldades já evidenciadas.

A questão estava então, assim como hoje, no fato que, para ter taxas de acumulação que o capital já não garante mais há décadas - pois se depara com a própria contradição da produção ser limitada - os agentes do capital teriam inflado e, desse modo, alterado artificialmente, a riqueza fictícia mundial como um grande balão aeróstato através de mecanismos fiduciários e apostas muito arriscadas ${ }^{3}$. A partir do momento em que um dos irmãos inimigos decide atacar um dos elos mais fracos, todos os donos dos títulos de valor inexistente percebem que são donos de lixo nas próprias contas públicas (por exemplo, os títulos da dívida da Grécia \& Companhia) e que estão muito próximos da falência. Para representar a dinâmica da economia capitalista, podemos pensar na metáfora do equilibrista que, para poder andar mesmo que por quilômetros por cima de um cabo, na primeira oscilação existe risco de queda e não conseguirá mais voltar à sua caminhada normal.

O capitalismo mundial acha-se, portanto, em condição crítica pela qual, perante a evidente contração da produção real mundial, encontra-se a lutar para o aumento, absoluto ou ainda mais relativo (alavanca financeira), da riqueza fictícia de posse geral, famílias e capitalistas, a qual somente se sustenta dado o clima precário de confiança suscetível de cair a qualquer momento.

As manobras de salvação acontecem graças ao simples deslocamento das dívidas (o assim chamado refinanciamento) em direção de sujeitos, eles mesmos altamente endividados, que mostram, porém, estabilidade maior em relação aos demais. A situação é tão complexa e precária, que só precisase encontrar um devedor aparentemente mais confiável para animar e estabilizar os mercados financeiros. Para o resto, em uma condição geral de crise, a estratégia do golpear e fugir (hit and run) torna-se central. Para complementar, são propostas políticas da chamada austeridade, que tratam de piorar drasticamente o valor de troca da força trabalho (no salário direto e no indireto), favorecendo, assim, a passagem de mais valia da classe subalterna em direção à dominante. Apesar disso, conforme a agência de serviços financeiros McKinsey \& Companhia. havia previsto, as operações de diminuição da dívida não são isentas de custos, até para o próprio capital, na maioria dos casos (cerca de 45) desde 1930, estas foram seguidas por uma recessão de dois a três anos de duração; na fase atual, foram muito piores.

Os resultados do quinquênio das políticas de austeridade ditadas pelo capital internacional e aceitas, de forma subalterna, pelos governos da denominada unidade nacional - Nova Democracia/ Pasok - geraram uma situação social e econômica totalmente insustentável para o povo grego. Somente para tutelar os lucros e os capitais dos credores, a classe trabalhadora local foi de fato sacrificada e em poucos anos vivenciou desemprego maciço, miséria e pobreza crescendo abruptamente, assim como reduções salariais desenfreadas. No final de 2014, indicadores estatísticos descreviam a Grécia como um país em desenvolvimento, aonde até muitos itens alimentícios e remédios não chegavam mais. Os governos eleitos, depois de terem aprovado as curas drásticas impostas pela troika, objetivando um saneamento que nunca se verificou, em menos de um quinquênio pioraram muito as condições de vida dos trabalhadores, favorecendo, por outro lado, armadores e senhores das condições de produção.

É opinião comum e compartilhada que, na mediada em que no programa de Salonicco de $2014^{4}$ tinha sido prometida drástica recusa das políticas de austeridade, o partido de esquerda Syriza havia sido eleito com a maioria dos votos e, junto com uma força política marginal (de direita, mas antieuropeia), este tinha conseguido, no começo de 2015, 
desenvolver um governo expressamente hostil às medidas impostas pelos credores internacionais até então. As esperanças eram muitas e o líder Tsipras parecia apto para mantê-las, apesar de membros do parlamento, como os do Kke, já previssem a inevitável falência das políticas propostas pelo partido vencedor.

\subsection{Clinamen grego}

Então, no dia 25 de janeiro 2015, um partido claramente de esquerda e hostil às políticas restritivas que tinham afogado o país, consciente da necessidade de cortar a dívida existente e de atuar outras reformas sociais (como, por exemplo, aumentar a aposentadoria mínima e recomeçar a pagar os salários do setor público), subia ao poder do país com mais dificuldade do velho continente. O êxito das eleições foi inequívoco: com quase $37 \%$ dos votos o desespero tinha levado os gregos a escolher Syriza, ou seja, a reprovar drasticamente aqueles partidos que haviam feito acordos, nos últimos cinco anos, com instituições supranacionais (representantes do capital e das instituições) sacrificando literalmente vidas em troca de hipotético saneamento (obviamente dando preferência à classe dominante) dos quais nunca se viram efeitos positivos.

Naquela ocasião, não foram poucos a intuir os perigos e os limites associados às políticas socialdemocráticas dos que pensam poder reformar um modo de produção baseado no domínio de classe, sem ter em conta as relações de força que, na fase atual, são extraordinariamente assimétricas e com certeza não favorece os trabalhadores. Portanto, quase em seguida começaram as contradições entre a troika e o governo grego em relação a como gerenciar a dívida que, enquanto isso, apesar das curas da Nea Demokratia e Pasok, tinha alcançado e superado $200 \%$ no tocante ao Produto Interno Bruto (PIB). No primeiro período de contratação, Tsipras e o então ministro da economia, Varoufakis, tinham, imediatamente, manifestados a vontade de não quebrar com a oposição, reiterando perante o Eurogrupo "[...] seu comprometimento inequivocável de honrar a própria promessa financeira a todos os credores, totalmente e rapidamente.", assim como o comprometimento em

[...] garantir o adequado avanço primário e a receita financeira necessária para garantir a sustentabilidade da dívida, alinhada à declaração do Eurogrupo de novembro 2012 (GRÉCIA..., 2015).

Em suma, uma estratégia de política econômica que, de alguma forma, já parecia contrastar com a famosa propaganda eleitoral de querer "[...] manter os banqueiros afastados das casas dos gregos." (GRÉCIA..., 2015).

Já são bem conhecidos os fatos que, menos de seis meses depois, determinaram a interrupção das contratações entre os ex-troika (já instituições) e o governo grego, evento que induziu o próprio premiê a consultar o povo sobre a oportunidade de seguir ou interromper a longa tratativa. Querendo resumir as propostas do governo grego, baseadas principalmente na recuperação da sonegação fiscal e o aumento dos impostos dos grandes patrimônios e dos capitais, entrara em choque com as exigências das instituições que queriam continuar a afetar os trabalhadores. Exigência a ser consumada mediante o aumento de impostos indiretos e sobre bens de primeira necessidade, corte de aposentadorias e salários dos empregados públicos, prolongamento da idade para a aposentadoria, quase imediato, e, por fim, depredando a comunidade de seus recursos estratégicos, através da privatização das poucas firmas públicas potencialmente rentáveis. Mais uma vez, como se tivesse necessidade, a Comissão Europeia, Banco Central Europeu (BCE) e, ainda mais, o Fundo Monetário Internacional (FMI), revelaram suas natureza e funcionalidade institucional, ou seja, a de tutelar o capital internacional, nas sedes institucionais, em claro detrimento da classe trabalhadora.

Não por acaso, foi logo a Lagarde (Presidente do FMI), segundo também afirmava nas declarações, a mostrar como o aumento da alíquota de taxação direta sobre os grandes capitais poderia ser uma medida com certo resultado fiscal, enquanto o que incidia sobre os trabalhadores teria conseguido resultado muito mais seguro. Atrás da obviedade dessas declarações (aumento das alíquotas fiscais diretas dos trabalhadores dependentes gera disponibilidade fiscal garantida, enquanto o que deriva dos patrimônios é muito volátil) vêse uma posição muito rígida, pois claramente classista. Visto que o próprio Tsipras teria se maravilhado publicamente por essa declaração, lamentando até a diferença nítida de tratamento com o que aconteceu no passado, em detrimento de Portugal e da Irlanda, a atitude de Juncker \& Companhia. foi excessivamente explícita na sua rigidez: substancialmente, foi reiterado que sobre os empréstimos não há descontos para ninguém.

Que grande fatia da população grega esteja já há anos em situação de pobreza absoluta, que os hospitais já não estejam mais em condições de fornecer tratamentos básicos; que nos mercados sejam vendidos produtos vencidos; que haja um exército de pessoas que mora já na rua estavelmente; e que perante tudo isso, armadores, homens e mulheres da grande finança internacional aproveitem todos os dias as magníficas ilhas do Egeu, não é considerado pelas instituições como um problema que precisa urgentemente de vingança, muito pelo contrário.

As instituições, de fato sujeitas à natureza superestatal, e órgãos de expressão da democracia burguesa, não diretamente eleitos através do voto, 
mostram, dessa forma, seu verdadeiro vulto: de fato neutralizaram a força do povo grego que já havia se decidido pela recusa das políticas de austeridade, concentrando o próprio voto no partido de Tsipras. O governo então regente carregava, sem dúvida, uma quantidade de contradições políticas difíceis de contar, começando pela excentricidade marxiana de Varoufakis, passando pela aliança com o grupo de direita, que garante a maioria no Parlamento, até a heterogeneidade interna, onde está o próprio Syriza. Apesar disso, precisamos reconhecer ao Tsipras, a Varoufakis e ao grupo dirigente que evidentemente os sustentaram - mesmo deixando claro que em posições social-democráticas - de terem conseguido, de certa forma, embaralhar as cartas de forma tão confusa que até deram a impressão de ter mudado as regras do jogo, encontrando-se, depois de meses, a ter que jogar a carta certa.

Retrocedendo ao início do ano, quando foi oficializado o êxito das eleições gregas, muitos, como já foi mostrado, declararam que teriam amenizado a presença do capital internacional que pesava sobre o povo grego, pulverizando-as com a troika, outros frisaram que o mesmo programa apresentado na campanha eleitoral seria irrealizável. Todas estas perplexidades, de fato, não eram infundadas, encontravam-se em uma situação determinada por relações de força muito desfavoráveis para Tsipras \& Companhia.

Apesar disso, mês após mês e reunião após reunião, cumpre-se, também, a afirmação política de Podemos em muitas cidades espanholas (sobretudo em Madrid e Barcelona), que sempre declarou colocar-se em continuidade política com o governo grego. O expediente tático de espera favoreceu aparentemente a parte que, desde o início, era objetivamente fraca e incapaz de formar uma agenda. Sinais de nervosismo, no final de junho, podiam ser sentidos em todos os níveis, o que tem a ver com a classe dominante e seus expoentes institucionais: grandes incertezas nos mercados europeus, e não só, a representação de uma segurança não mais sólida na conclusão de acordos. Por uma estranha combinação de eventos, parecia como que Tsipras e Varoufakis tivessem colocado do avesso as regras do jogo, sendo sua vez a próxima decisão. Assim, perante a enésima provocação do capital, resolveram que fosse o povo grego a ter que decidir sobre a própria sorte, convocando o famoso referendo do dia 5 de julho.

\subsection{Por que a Grécia}

Talvez seja útil examinar as razões da rigidez intransigente exibida por instituições supranacionais durante as negociações. De fato, como muitos estudiosos têm observado, as condições punitivas propostas para o bail-out da Grécia foram, provavelmente, não necessárias para evitar o risco de contágio em todo o continente. Isto por duas razões: primeiro, porque a Grécia não tem um peso específico que influencie toda a estrutura económica da União Européia (EU) ou, mais ainda, o resto do mundo. O PIB não é muito diferente do que o da região do Lázio, mas é menos do que o da região da Lombardia, e sua dívida ultrapassa só um pouco mais de $10 \%$ da dívida da Itália toda. A outra razão é que, a partir de setembro de 2009, para apresentar praticamente todos os títulos do governo grego (junk bonds), foram retirados dos orçamentos de capital privado, porque adquiridos do setor público pelo privado por meio das ferramentas fornecidas por Draghi e do BCE.

$\mathrm{Na}$ verdade, os capitais mais expostos, como já se enfatizou, foram aqueles da França (79 € bilhões) e, posteriormente, os da Alemanha (45€ bilhões); em seguida os holandeses (12 $€$ bilhões) e italianos ( $7 €$ bilhões); mas, acima de tudo, é importante lembrar que foi apenas por entidades privadas. Com uma operação extraordinária, em termos de classe, em poucos anos o pilar desses títulos foi redistribuído entre os orçamentos dos quatro países com o maior PIB. Violando proporções mostradas anteriormente, chegou-se a situação em que os alemães atualmente detêm a maior parcela de títulos (62 $€$ bilhões do setor público, 14 bilhões do privado); a seguir a França (47 bilhões só no setor público), Itália (41 mil milhões de euros, do setor público) e Espanha (27 bilhões do setor público). Em suma, foi confirmado, mais uma vez, que a lei de privatização dos lucros e socialização das perdas torna-se essencial especialmente durante períodos de crise; e que o fundo salva-estados, que é a base dessa manobra, descarregou sobre os dois PIIGS mais importantes (Itália e Espanha) a maior parte do peso destes títulos de alto risco e, acima de tudo, sobre o seu setor público.

Portanto, juntando os dois elementos, o baixo peso relativo da economia grega e de seu endividamento e o fato de que este último foi agora transferido do privado para o público, se vê que as dúvidas sobre a oportunidade (para a capital local) para tal obstinação são muitas. A cisão do capital privado dos riscos associados aos títulos de dívida gregos, pelo menos em teoria, poderia levar as instituições a assumir uma atitude menos rígida e mais colaborativa. Em vez disso, o fechamento absoluto por parte da BCE, do FMI e da Comissão Europeia - mesmo que as propostas do Governo Grego tenham sido formuladas às vezes não completamente transparentes - parece inspirado por um dogmatismo excessivo difícil de conciliar com os interesses do capital local, especialmente se, como no caso presente, há pouco a se perder. Além disso, torna-se difícil para a capital e seus lacaios, legitimar aos olhos do público uma situação continental em que as instituições, lideradas pelos Estados mais ricos do continente, continuariam a assediar pesadamente um país já golpeado e em crise humanitária há pelo menos cinco anos. 
Essas razões, portanto, corroboram a hipótese de uma estratégia de dissuasão contra futuros episódios de recaídas ao cumprimento dos compromissos orçamentais - que é semelhante ao famoso ditado italiano, Eu falo com a nora para a sogra entender. Em essência, a atitude aparentemente irracional e contraproducente teria como objetivo principal a correspondente ibérica, Podemos. A Espanha, apesar da grave crise que tem enfrentado, continua a ser a décima potência mundial, a quarta em termos de PIB, na Europa, depois da Alemanha, França e Itália.

Claramente, cada escolha poderia ter implicações muito mais significativas ao longo de toda a estrutura de capital não somente com base no euro, mas também a nível mundial. Portanto, os músculos mostrados ao governo grego poderiam ter agido principalmente como elemento de dissuasão contra as ambições, comumente chamado de antiausteridade, de um eventual governo ibérico liderado pelo Podemos (as eleições gerais estão agendadas para o dia 20 de dezembro e os resultados de Madrid e Barcelona a este respeito levam a uma reflexão). No entanto, as coisas parecem ter sido colocadas em um plano mais inclinado e menos controlável pelo capital ligado ao euro e ao dólar. Talvez, ingenuamente, eles não tenham chegado a um acordo com as possíveis consequências dos irmãos inimigos da Organização de Cooperação de Xangai, sabidamente a Rússia e a China.

Desde o novo governo, o capital russo, personificado por Putin, tem sido condescendente em relação à Grécia, por ter se colocado explicitamente como uma alternativa crível para o punho de ferro da troika. Já nas primeiras semanas após a eleição, eram frequentes as reuniões entre os dois presidentes. Foram muitas as declarações públicas de Putin que afirmava ser capaz de fornecer liquidez suficiente para o sistema bancário grego, mesmo que as negociações com FMI, BCE e da UE pudessem não ter êxito. As relações nos meses a seguir foram mais frequentes, acima de tudo para a posição estratégica da Grécia, no Mediterrâneo. No início de abril deste ano, a Companhia chegou a um acordo para a construção de um gasoduto, que, uma vez abandonado o projeto South Stream (também e acima de tudo, para os (poucos) conhecidos eventos da Ucrânia), levará, através da Turquia (os acordos foram assinados com Erdogan), o gás russo ao coração da Europa. A este respeito, as finanças gregas poderiam se beneficiar com a antecedência substancial para a construção do chamado Stream turco, que representaria uma alternativa viável à usura, disfarçado como um empréstimo, o FMI, etc.

A partir desse ponto de vista, a abertura de crédito - por enquanto exclusivamente verbal - pelo banco que teria se formado dentro dos Brics (Brasil, Rússia, Índia, China e África do Sul), o que obrigou Tsipras a alegrar-se argumentando que "[...] a Europa não é mais o centro do mundo.", sugere que as cartas colocadas à disposição do Governo Grego não são tão triviais. Especialmente considerando a recente (29 de junho) saída do primeiro-ministro da China, Li Quekiang, que questionado sobre o assunto, em termos inequívocos, afirmou que tanto quanto o da dívida grega, "[...] a China está pronta para desempenhar um papel ativo." apenas porque a eventual Grexit seria um problema global e não apenas europeu. Também e de fato é do "[...] interesse da China que a Grécia permaneça na zona do euro.", como parceira comercial e uma crise do euro acabaria por ter repercussões significativas, também, na República Popular da China (SCHETTINO, 2015b).

Em seguida, o assunto não deve ser deixado de fora Pireu, o porto mais importante do Mediterrâneo, que durante décadas foi alvo do objetivo do capital não chinês, o controle que garantiria a posse de um direito estratégico e altamente rentável no coração da Europa e do território afetado pelo acordo TTIP (comércio transatlântico e parceria de investimento).

Portanto, na questão se entrelaçam conflitos interimperialistas que caracterizam o atual estágio do modo de produção de capital e que, nos já numerosos cenários de guerra explícita (Médio Oriente, Ucrânia etc.), eles veem somente a aparência externa de um fenômeno econômico muito mais complexo, caracterizado pela contraposição do capital do dólar/EUR com os estados envolvidos na Organização de Cooperação de Xangai, na China, e na Rússia, em particular. É precisamente por esta razão, sabidamente para evitar que um estado como a Grécia, que também tem um simbolismo importante para a história da Europa, pudesse vir a ser envolvida em áreas de influência hostil imperialista. Obama falou enfaticamente, pedindo a Juncker fazer de tudo para evitar tanto a saída quanto o default da política monetária única e, portanto, a UE.

Perder ainda que um pedaço, mesmo que insignificante, do parceiro (por assim dizer...) do acordo TTIP desestabilizaria um dos elementos que devem reforçar o capital dos Estados Unidos (para um dano ligado ao euro) contra o asiático. De fato, há também a lembrança da vitória pelo capital atrelado ao dólar sobre o inimigo ligado ao euro, irmão na guerra, que identificou o primeiro ato de hostilidade explícita em fevereiro de 2010 com o ataque especulativo logo sobre a dívida pública grega.

A preocupação dos governantes do mundo é o fato de que esta situação de extrema instabilidade se materialize em um momento de extrema fragilidade da economia mundial. Basta observar a tendência da bolsa e, portanto, a maior parte do capital fictício, para entender como as declarações de recuperação, o fim da crise e assim por diante, foram fumaça vendida por bajuladores da capital, no início de cada ano, tentando encobrir a realidade ilusória com truques de ilusionismo.

Mesmo Martin Wolf - comentarista histórico e influente colunista do Financial Times em 
fatos econômicos - começou a insistir sobre a inevitabilidade da grave deterioração das condições já críticas. Do seu ponto de vista, de fato, a resolução de uma crise com base em dívida, aparentemente foi resolvida com mais dívida (ou seja, quantitativos easing EUA, europeu e japonês), inflando ainda mais a bolha do capital fictício, que, de acordo com os cálculos feitos pelos peritos, é ainda mais carregado com bonds lixo em comparação com 2007/2008. Resumindo: apesar das muitas declarações de governos de todo o mundo (por exemplo, a Lei Dodd-Frank), a quantidade de produtos derivativos tóxicos aumentou consideravelmente graças aos que garantiram liquidez a preços baixos.

Como escrito repetidamente na revista La Contraddizione, devido a uma crise de superprodução e, portanto, a falta de pontos de venda de bens e produtos de capital, as imensas dificuldades de acumulação de capital obrigam o capital-dinheiro a lucrar através da especulação, tornando-se, assim, capital fictício (ou seja, não capitais, sua negação) e não em bens de capital, tentando acumular, ignorando a produção de valor e mais-valia (SCHETTINO, 2015a). E a isso é preciso acrescentar que, ao contrário dos pósLehman Brothers, ao menos dois instrumentos de política monetária serão excluídos: em primeiro lugar, a entrada de nova liquidez (pelas razões já vistas), e especialmente a da alavanca de taxa de juros que, em 2008, tinha uma média de cerca de $7 / 8 \%$ na Europa, e EUA foi suscetível a uma redução para estimular novos investimentos (que, como mencionado acima são apenas uma pequena parte da natureza produtiva); hoje beira o zero e, portanto, não poderá estar sujeito a novos cortes.

\section{A REVERSÃO DO REFERENDO E DO MEMORANDO}

Nesse cenário amadurece o coup de théâtre do dia 25 de Junho. Confrontando a intransigência dos credores, Tsipras enfrenta a escolha entre aceitar as condições punitivas de bail-out, impostas pela Troika, traindo, assim, o programa eleitoral de Syriza, que tinha construído o seu sucesso, ou, alternativamente, abandonar as negociações e se aventurar em águas desconhecidas e, possivelmente, perigosas do default. Sua escolha de consultar a população sobre a proposta feita pelo acordo Troika é, em essência, uma tentativa desesperada de escapar das garras deste ou do outro, buscando no apoio popular a força política para quebrar a rigidez dos credores.

Em um nível mais profundo de leitura, a estratégia do referendo revela claramente a chance de tentar jogar em contradição latente dois pilares da superestrutura jurídica e ideológica sobre a qual repousa a legitimidade das democracias liberais: o axioma central do ius mercatorum (as dívidas são pagas) e os sistemas de axiomas centrais constitucionais Ocidentais (o povo é soberano). O raciocínio que dirige Tsipras para a consulta popular se baseia na ideia de que os órgãos representantes do capital internacional - apesar de serem deputados institucionalmente para garantir a aplicação do primeiro axioma - não pode ir tão longe a ponto de negar toda a segunda. Se o fizessem, eles acabariam por desmantelar suas bases, um dos principais mecanismos de controle ideológico da classe subalterna: a promessa, contida no pacto social que rege todo o Ocidente, para ser, em última análise, dona do seu próprio destino. Tsipras então tenta insinuar-se nas dobras desta contradição, contando com a suposta impossibilidade do estabelecimento de rasgar completamente o véu que esconde a verdadeira natureza das relações de produção aos olhos do público europeu.

O anúncio do referendo, de fato, produz o resultado de bagunçar os papéis do capital financeiro internacional e seus apêndices institucionais. No dia 29 de junho começou uma semana de fibrilação nos mercados de ações ao redor do mundo. Segundafeira Negra para bolsas de estudo e Tempestade grega das finanças: alguns dos títulos dos principais jornais financeiros quando os mercados reabriram após a interrupção das negociações. Na Europa, eles queimam em um dia $287 €$ bilhões em capitalização. Depois de longo período de estabilidade, os spreads da Itália e da Espanha aumentam abruptamente. Mesmo as listas de Wall Street e Tóquio são de cor vermelha. Pela primeira vez, em mais de uma década, uma sombra da luta de classes toca as instituições de governo da economia ocidental, quebrando-se naquele momento a unidade monolítica de propósitos e abrindo as comportas para reações em ordem confusa.

Parece claro, em particular, nos dias antes do referendo, a preocupação do governo norteamericano, que - em oposição à posição de linha-dura tomada pela Comissão Europeia e do Eurogrupo (não há negociações antes do voto) - se ativa novamente e diplomaticamente com o objetivo de reatar os fios das negociações. Já foi mencionada nas páginas anteriores a preocupação da administração Obama em manter a integridade do bloco geopolítico e comercial ocidental. Para isso, provavelmente, deve ser adicionado à luz do confronto entre a Troika e governo grego, a preocupação com o resultado do referendo, o que pode acabar radicalizando ainda mais o confronto, fazendo então o default grego inevitável e provocando um efeito dominó nos mercados financeiros de proporções imprevisíveis.

A reação das instituições na capital continental, no entanto, foi imediata. Primeiro, a liderança política e econômica da zona euro decidiu intervir abertamente na dialética do referendo, constituindose essencialmente como parte do debate, ao tentar transformar a votação em legitimidade popular às condições impostas à Grécia. Estamos testemunhando, assim, uma extensão curiosa do 
uso do instrumento para o papel democrático da transformação do conflito entre credores e devedores.

Provavelmente, pela primeira vez na história da democracia, os credores tentam convencer os devedores a aceitar espontaneamente, através de votação, a desapropriação à qual foram levados. Obviamente, é uma mera fase de ficção: o apelo ao voto dos cidadãos gregos a partir de Presidente da Comissão Europeia Juncker é apenas a última tentativa do capital de não despir, completamente, a cobertura ideológica da soberania popular. $\mathrm{Na}$ verdade, como ele se aproxima da mesa para se juntar ao jogo de roleta do referendo, o capital já está viciando o mecanismo que gira a roda, tentando influenciar a opinião pública grega através de uma chantagem financeira explícita.

Nos dias imediatamente anteriores à consulta, o BCE parou de fornecer liquidez ao sistema bancário helênico, obrigando o governo a fechar os bancos e tomar medidas de racionamento de dinheiro. As filas na retirada tornaram-se a imagem paradigmática do drama do povo grego. Através daquelas imagens apresentadas com repetição obsessiva pelos meios de comunicação burgueses nos dias da campanha do referendo - o estabelecimento carrega em toda a opinião pública continental uma pedagogia econômica brutal em que a punição exemplar está tendo que ser feita. O objeto que simboliza a capacidade de controlar os bens é subliminarmente associado à arrogância das pessoas que se atreveriam a fugir aos seus deveres e burlar suas leis, reivindicando o direito de decidir livremente seu próprio destino. Claro aviso dirigido a qualquer um que, no futuro, viesse a contestar a soberania dos chefes em nome da soberania popular.

No entanto, o povo grego resiste às ameaças e chantagens e, por grande maioria (61\%) reprova a proposta do acordo com os credores. É um resultado de significativa importância histórica. Pela primeira vez, o eleitorado de um país membro da zona euro veta uma moção de confiança contra o pacto de austeridade. Os cidadãos gregos, em essência, não interiorizam o sentimento de culpa que a propaganda burguesa tenta há anos impor-lhes, com as recorrentes acusações de preguiça, improdutividade e propensão para o desperdício. A vitória do OKI reenvia essas alegações para o remetente e se esforça, implicitamente, para que a estratégia de rigor financeiro perseguido obstinadamente pela Europa seja priorizada.

Tsipras parece ter ganhado a aposta. O resultado da consulta referendaria o encobrimento, na verdade, de um poder de negociação que nunca teve. Partindo para Bruxelas, ele disse que estava confiante em conseguir levar para casa, brevemente, um acordo decente. Mas, nos dias seguintes logo desapareceram os tons de otimismo. A oligarquia financeira, que governa a Europa, tira a sua máscara e revela o caráter sem qualquer vergonha do jogo democrático, em que ele fingiu participar.
Após a demonstração de força posta em prática na semana antes do referendo, a ameaça de fechar a torneira da liquidez é mais do que nunca credível, e é apenas necessário deixar isso se prolongar na negociação como para direcionar o resultado. Pelo contrário, com o desaparecimento de Varoufakis, o governo grego aceitou, em substância, mostrar-se à mesa das negociações sem a ameaça de Grexit, ou seja, a arma apontada para sua cabeça com que o ministro da economia grego tinha ameaçado por seis meses os colegas do Eurogrupo. Agora, armado apenas pela legitimidade derivada do consentimento de seu povo, e não mais pela flexibilidade estratégica conferida pelo famoso Plano $B$, Tsipras e a delegação grega, em seguida, vão à deriva às salas de Bruxelas, tornando-se presa fácil para a ganância do capital.

Além disso, os chefes de governo europeus têm todas as cartas para facilmente lembrarIhes que a democracia direta é um jogo válido somente dentro dos limites do Estado-nação, e que a organização supranacional de um povo não pode acreditar que podemos impor a sua vontade aos outros 18 que o compõem. Ademais do uso claramente instrumental feito naquela circunstância, este argumento, no entanto, tem o mérito de destacar toda a ambiguidade da retórica da soberania popular e da fraqueza implícita a adotá-lo como uma arma exclusiva para conflito interior de uma dialética política obviamente complexa, onde o próprio mecanismo da representação de interesses em um nacional ajuda a esconder a natureza da classe do conflito.

A semana de negociações após o referendo tem como êxito o conhecido Memorando do dia 12 de julho. A delegação grega capitulou, basicamente, em cada porta da frente em Atenas, um acordo de lágrimas e sangue. As condições previstas para o acesso ao financiamento de $€ 86 €$ bilhões desembolsados pelo ESM são realmente pesadas. O governo aceita um aumento substancial da taxa de IPVA sobre os principais bens de consumo e também se compromete a suprimir, até 2016, o regime privilegiado para as ilhas. São abolidos os subsídios aos combustíveis para os agricultores, a causa do tratamento fiscal não preferencial para os agricultores e proprietários. A taxa de impostos sobre o rendimento das pessoas coletivas passa de $26 \%$ para $28 \%$, a de imposto de luxo de $10 \%$ para $13 \%$ com efeitos retroativos a 2014 . O orçamento de defesa vai ser aliviado de $€ 100.000 .000$ em 2015 e 200 milhões em 2016.

O governo também se comprometeu a apresentar fortes desincentivos e penalizações por reforma antecipada, aumentar gradualmente a idade de aposentadoria para 67 anos, em 2022, e abolir a contribuição de solidariedade para as pensões mais pobres, em 2019. Compromissos explícitos também sobre as privatizações de qualquer das principais infraestruturas logísticas: o porto de 
Piraeus, os portos de Salónica e Hellinikon, as ferrovias estaduais e aeroportos regionais devem ser transferidos para mãos privadas, nos primeiros meses de 2016. Por fim, o memorando promete a aprovação do governo de um pacote de reformas do mercado de trabalho (a ser acordado com a Troika) voltada, principalmente, para enfraquecer o papel da negociação coletiva na determinação dos salários. O desembolso das parcelas do financiamento está sujeito ao cumprimento obrigatório com este programa.

Define-se, além disso, a obrigação para o governo de "[...] consultar a União Europeia, FMI e BCE para todas as ações necessárias para cumprir o acordo antes de se tornarem lei." concordando teor, o calendário e os métodos de reforma (SCHETTINO, 2015b). Ainda assim, o governo grego está impedido de adotar medidas para regulamentar o sistema bancário sem primeiro consultar a Comissão Europeia e o BCE. Finalmente, para garantir o reembolso do empréstimo, o governo precisa instituir um fundo de confiança em que sejam depositados os respectivos bens públicos a serem privatizadas. O fundo será gerido por um conselho de especialistas gregos, mas sob a supervisão das instituições europeias. Um panorama que enquadra a Grécia em uma imagem de um protetorado por parte de um Estado soberano, como alguns comentadores não deixaram de observar. Que a democracia tenha concluído o curso de sua vida para ir morrer, curiosamente, na mesma cidade onde também nasceu?

4 CONCLUSÃO: rumo à crise da democracia burguesa?

O conflito interimperialista é, a nosso ver, a figura característica da atual fase histórica do capitalismo. O bloqueio do capital atrelado ao dólar há quase uma década no vórtice de dramática crise de rentabilidade - está envolvido em um esforço intensivo para construir redes de viabilidade de escala supercontinental, onde pode dar liberdade às próprias energias, sujeitando à sua influência áreas e sectores ainda protegidos da concorrência em um comércio global. Este esforço envolve - na medida em que ele seja bem sucedido - uma crise sistemática dada à transferência da própria crise em direção de áreas comercialmente e financeiramente contíguas pela mesma divisa.

O bloco do capital ligado ao euro, não podendo evitar encontrar-se no meio da tempestade, é forçado a defender-se da concorrência de produtos norteamericanos, e (especialmente) das almôndegas envenenadas que os bancos norte-americanos vêm lançando através de pacotes de ativos tóxicos que vagueiam o mundo escondidos no tráfico dos hedge founds. E a única defesa possível, dentro das condições de produção existentes, é alcançar um (simétrico) esforço de racionalização das suas redes comerciais, 0 que resulta em facilitar 0 acesso dos grandes líderes dessas multinacionais aos mercados locais (liberalização) e eliminar os restantes bolsões de resistência ao domínio da lógica comercial (privatização). Em outras palavras, aprofundar as condições de exploração do trabalho e baixar a contradição dos sistemas sub-regionais periféricos.

Corolário institucional fundamental deste modelo de gestão de crises é a subtração da soberania dos povos das alavancas nevrálgicas da economia e das finanças. Não é por acaso que a autonomia dos bancos centrais e a retirada de capital da propriedade pública das indústrias estratégicas foram temas centrais no debate das últimas duas décadas. De fato, uma enorme quantidade de propaganda (disfarçada como enquete) tem contribuído para a formação de uma sólida base de apoio à resolução da prática da democracia nos assuntos relativos à gestão da economia.

Mas, o bloqueio do capital europeu, além do esforço daqueles que buscam montar essa superestrutura ideológica, dedicou compromisso igualmente importante em formar ainda uma superestrutura jurídica consistente com as emergências deste momento histórico. A arquitetura dos poderes da política econômica, projetada em Maastricht, em 1991, por ocasião da instituição da moeda única, reduz, de fato, a soberania fiscal dos Estados-membros a mero instrumento para apoiar a moeda e, ao mesmo tempo, subtraindo a soberania monetária para o controle democrático, atribuindo-a aos tecnocratas que são expressão dos salões de financiamento continental e dirigindo a ação explicitamente com a meta de cristalizar a distribuição da riqueza determinada pelo mercado.

Dentro desta estrutura, as necessidades da comunidade de Estados periféricos são esmagadas irremediavelmente e presas a um papel de hierarquicamente subordinados às economias dinâmicas do centro. Incapazes de utilizar as alavancas de desvalorização ou a se beneficiar de mecanismos de redistribuição fiscal para ajustar os desequilíbrios comerciais, os Estados periféricos da zona do euro acabam, sistematicamente, subjugados ao domínio da dívida. Assim, a moeda única revela, inequivocamente, a natureza de instrumento de afirmação dos interesses do capital financeiro estrangeiro contra aqueles das empresas nacionais. Não só a classe trabalhadora torna-se miserável pela destruição do Estado social, a privatização gradual dos serviços públicos essenciais, a queda dos salários e o aumento acentuado dos impostos: o capital local também é atacado pelas liberalizações e incorporado em grupos de conglomerados que em tamanho e poder de fogo - são cada vez menos passíveis de controle consciente das comunidades em cujo território eles insistem.

Nesse contexto, a democracia burguesa é, portanto, cada vez mais reduzida a um ritual substancial sem sentido. O povo grego, que já se 
declarou duas vezes em poucos meses de forma inequívoca contra as políticas de austeridade impostas por Bruxelas, encontrou-se a ter que engolir um programa de reformas estruturais radicais associadas a ajustes fiscais drásticos, cujos impactos em termos económicos e sociais são susceptíveis de serem devastadores.

Esmagado entre a adesão às demandas das instituições representativas do bloco de capitais do continente e o respeito à delegação atribuída pelo eleitorado, o governo grego vem resolvendo o conflito curvando-se às chantagens e endossando, neste momento, o regime de suspensão à soberania democrática que, ao mesmo tempo, não se encontra com nenhuma legitimidade nas mentes constitucionais dos Estados membros, nem nas dobras do Tratado da EU; agora está se tornando um padrão recorrente para resolver o conflito endêmico entre as instituições representativas das elites econômicas e as instâncias das classes subalternas.

Apesar das diferenças formais, a história da política da Grécia parece, de fato, muito diferente da italiana, onde, já desde 2011, a seleção da liderança política do país foge à regra de encontrar sistematicamente a preferência do eleitorado e não foge (ao que parece) à regra não escrita da investigação das organicidades (no sentido gramsciano) dos desejos da burguesia financeira continental. Portanto, o adjetivo burguês é inteiramente apropriado para caracterizar o estado atual da democracia na Europa.

A história escrita nos últimos meses sobre a fraca ligação entre Atenas e Bruxelas demonstra inequivocamente que o capital é mais forte do que a vontade do povo, e que o mecanismo de representação democrática não é capaz de proteger a classe trabalhadora da opressão à qual a burguesia europeia está se sujeitando. E, no entanto, a história escrita nos últimos meses também nos revela outra coisa: a história da Grécia rasgou o véu da soberania do povo que cobria a verdadeira natureza da relação entre as classes, e que demonstrou sem mais possibilidade de dúvida, que a Europa é um projeto liderado pelo capital e que se dobrou às suas prioridades estratégicas, contrárias aos interesses das classes subalternas e não muito sutilmente encoberto por atitudes autoritárias. Em suma, o imperador está despido. E é nas dobras de sua nudez que se deve procurar o espaço para aprofundar a contradição.

\section{REFERÊNCIAS}

FITOUSSI, J. P. Le Théorème du lampadair. Paris: Editions Les Liens qui Liberènt, 2013.

GRECIA, le condizioni dell'Eurogruppo: 3 giorni per le riforme e pignoramento dei beni pubblici per 50 miliardi. II Fatto Quotidiano.it, Roma,
2015. Disponível em:<http://www.ilfattoquotidiano. it/2015/07/12/grecia-le-condizioni-delleurogruppo3-giorni-per-le-riforme-e-pignoramento-dei-benipubblici-per-50-miliardi/1866962/>. Acesso em: 1 out. 2015.

KRUGMAN, P. End This Depression Now! New York: W.W. Norton \& Company, 2012.

SCHETTINO, F. A última crise: desde o colapso de Lehman Brothers até a questao da divida publica europeia. Revista de Politicas Publicas, São Luís, n. esp., p. 161-170, jul. 2014.

II Bazooka, l'Europa e la bolla: quantitative easing, crisi europea e conflitto valutario. La Contraddizione Online, Roma, n. 150, ed. esp., p. 24-37, 2015a.

II Clinanem greco: riflession sulla questione greca e le potenzialli conseguenze. La Contraddizione, Roma, n. 6, apr./gui. 2015b. Disponível em:<https://rivistacontraddizione. wordpress.com/2015/07/02/il-clinamen-greco/>. Acesso em: 1 out. 2015.

STIGLITZ, J. E. How I would vote in the Greek referendum. The Guardian, London, 29 june 2015. Disponível em:<http://www.theguardian.com/ business/2015/jun/29/joseph-stiglitz-how-i-wouldvote-in-the-greek-referendum?CMP=share_btn_ $f B>$. Acesso em: 1 out. 2015

VAROUFAKIS, Y. The Global Minotaur: America, the true origins of the financial crisis and the future of the world economy. London: Zed Books, 2011.

PULLIAN, S.; KELLY, Kate; MOLLENKAMP, Carrick. Hedge funds try to "career trade" against euro. Wall Street Journal, [S. I.], feb. 2010.

\section{NOTAS}

1 Traduzido do italiano por Tina Raffaella Lucente.

2 Pode consultar-se, por exemplo, Stiglitz (2015).

3 Para interpretações da recessão global atualmente em ato que, mesmo adotando linguagem e metodologia ortodoxos, compartilham uma leitura do papel da finança como supletivo em relação à exigência de garantir as condições de produção capitalista (FITOUSSI, 2013; KRUGMAN, 2012; VAROUFAKIS, 2013).

4 Disponível em:<http://www.syriza.gr/article/SYRIZA--THE-THESSALONIKI-PROGRAMME.html>.

Salvatore D'Acunto

Economista 
Doutor em Economia e Política Direito pela Seconda Università degli Studi di Nápoles (SUN)

Professor Associado de Economia na Faculdade de Direito da SUN.

E-mail: salvatore.dacunto@unina2.it

\section{Francesco Schettino}

Economista

Mestre em Economia pela University of

Rome "La Sapienza"

Professor Assostente de Economia no Decpartamento de Direito da Seconda Università degli Studi di Nápoles

(SUN)

E-mail: francesco.schettino@unina2.it

Seconda Università degli Studi di Nápoles - SUN

Via Antonio Vivaldi, 43, 81100 Caserta CE, Itália 